\title{
Perceptions of the impact of an advanced training programme on the management skills of health professionals in Gauteng, South Africa
}

\author{
J Mutyabule, ${ }^{1,2}$ RN, MPH; F Senkubuge, ${ }^{2}$ MB ChB, MMed; D Cameron, ${ }^{3}$ MB ChB, MPraxMed, MPhil; V Pillay, ${ }^{4}$ MBA, PGCHE; P Petrucka, ${ }^{5}$ RN, PhD \\ ${ }^{1}$ School of Nursing and Midwifery, Aga Khan University, Kampala, Uganda \\ ${ }^{2}$ School of Health Systems and Public Health, Faculty of Health Sciences, University of Pretoria, South Africa \\ ${ }^{3}$ Department of Family Medicine, Faculty of Health Sciences, University of Pretoria; and Foundation for Professional Development, Pretoria, South Africa \\ ${ }^{4}$ Foundation for Professional Development, Pretoria, South Africa \\ ${ }^{5}$ College of Nursing, University of Saskatchewan, Canada; and Academics without Borders (East Africa), Canada
}

Corresponding author: P Petrucka (pammla.petrucka@usask.ca)

Background. South Africa's health sector spans the private and the public sectors. Within the sectors, health managers take on strategic leadership roles without formal training in management or leadership - a trend more common in the public sector than the private sector. Health managers are selected based on their clinical skills rather than their leadership or management skills.

Objective. To compare self-rated competencies in management and leadership before and after training of the participants; to assess participants' experience of the training programme; and to evaluate the management and leadership skills of the participants after training.

Methods. A cross-sectional, descriptive analytical method and $360^{\circ}$ interviewing were used in this study. Participants were evaluated $\sim 18$ months after completion of the training programme. A $360^{\circ}$ evaluation $\left(360^{\circ} \mathrm{E}\right)$ of six of the 12 leadership/management competencies was done with the supervisors, colleagues, and subordinates of the participants.

Results. All participants rated themselves as improved in 12 managerial and leadership competencies. The $360^{\circ} \mathrm{E}$ affirmed five of these competencies as improved, with the ability to create and implement a marketing plan rating poorly.

Conclusion. Training in management leads to improvement in both leadership and managerial skills of health professionals.

Afr J Health Professions Educ 2017;9(3):133-137. DOI:10.7196/AJHPE.2017.v9i3.696

Few medical and nursing professionals are formally trained to be leaders and managers; yet, such individuals are often called upon to assume these roles. ${ }^{[1-3]}$ Traditionally, health professionals assumed managerial or leadership positions based on their clinical and scientific merits; attributes that do not necessarily equate to competency or aptitude as a leader or manager. ${ }^{[4]}$ Consequently, there is frequently a perceived failure to perform or significant discontent with role fulfilment.

Health providers generally expect straightforward, logical answers to every problem. These qualities may be appropriate for a clinical leader, but not so for a leader in the high-pressure business environment of healthcare, which is unpredictable, competitive and imbued with interdisciplinary conflicts, possibly making such leader incompetent. An incompetent leader often has an impact on subordinates by creating a stressful working environment and by the inability to achieve organisational objectives. ${ }^{[2,3,5,6]}$ Thus, health managers/leaders experience poor job satisfaction and poor retention, impacting negatively on an organisation in terms of fiscal and human resources and organisational history. ${ }^{[7]}$

Previously, health professionals moved from being a practitioner to a leader by virtue of clinical seniority - an approach that no longer reflects the realities of the health sector. 'With the increasing complexity of health systems, the diversity of the roles and responsibilities that befall a medical manager subsequently have broadened, requiring the individual with a wider range of training and expertise than just seniority. ${ }^{\text {'[8] }}$ There is growing evidence of the positive impact of formal training of health professionals in management and leadership. ${ }^{[9]}$
South Africa (SA) has prioritised healthcare management capacity building by enacting a skills development plan, as deficiencies in managerial capacity, especially in the public sector, have been identified as a risk. A survey of all managers in registered public and private hospitals in SA, found that $94.9 \%$ of public and $80.5 \%$ of private sector managers identified a need for further training in management skills development. ${ }^{[10]}$

The SA National Strategic Plan prioritises the training of managers (i.e. chief executive officers, senior/district managers) to be based on a proposed assessment and gap analysis of competencies of current managers in healthcare. ${ }^{[11]}$ Competency is defined as a cluster of related knowledge, skills, and attitudes that can be: (i) measured; (ii) compared with known standards; (iii) correlated with job performance; and (iv) improved by education and training. ${ }^{[1]} \mathrm{A}$ call for competency-based education in health management has emanated from professional practitioner groups, researchers, educators, and accreditation bodies. ${ }^{[12]}$

The Foundation for Professional Development (FPD) offers an accredited short course - the Certificate in Advanced Health Management (CAHM). This 1-year course links course modules and assignments to participants' work environments to optimise practical and reflective opportunities. The exit learning outcome of the CAHM is to enable participants to apply management principles at a strategic level within the healthcare environment to optimise healthcare in SA. ${ }^{[12]}$

The cohort for 2009 completed their training in 2010. This study investigated the impact of the CAHM course $\sim 18$ months after training. 


\section{Methods}

\section{Study design and sample size}

This was a cross-sectional, descriptive analytical study of those who completed the 2009 CAHM. Data were collected using self-administered electronic questionnaires comprised of both multiple-choice and open-ended questions; the responses where deductively analysed. The questionnaire was developed by the researcher (JM) and piloted among her colleagues at FPD who had completed the CAHM.

A $360^{\circ}$ evaluation $\left(360^{\circ} \mathrm{E}\right)$ was conducted with supervisors, colleagues and subordinates as assessors. It is now popular for assessing employee performance in the private and public sectors, as it involves seeking opinions from a spectrum of stakeholders well positioned to reflect on the employee's job performance and effectiveness. The $360^{\circ} \mathrm{E}$ gathers perceptions, from those directly affected, about an employee's behaviour and the impact of his/her behaviour on job effectiveness. The advantages of the $360^{\circ} \mathrm{E}$ include minimising performance-appraisal errors, and providing a broad-scoped assessment and improved assessment reliability.

The questionnaire was sent electronically to all CAHM-qualified doctors and nurses $(n=17)$ and participants' assessors $(n=51)$. Although the CAHM participant intake was 44, only 17 were health professionals. Sixty-eight participants were surveyed, with 40 responses (59\% response rate), of whom $10(25 \%)$ were CAHM trainees and $30(75 \%)$ assessors.

\section{Data collection and measurement}

The questionnaire assessed 12 self-rated competencies across 11 domains of leadership and management (Table 1). The 11 domains reflect emotional intelligence, and interpersonal, technical and conceptual/analytical abilities of the participants.

Data collection included demographic information, number of staff supervised, annual operating budget for which they are responsible, and if the participants received management training before CAHM. Data relevant to the CAHM course were also collected, such as the participants' personal highlights, relevance to their work, recommendation to other managers in the health sector, influence on achieving organisational strategic objectives, impact of training on their work, and any changes with regard to salary, job promotion, and/or increase in responsibilities.

\section{Data analysis}

Data were entered into Epi Info (Centers for Disease Control and Prevention, USA) and then exported to Stata 11 (StataCorp., USA) for analysis. Frequencies calculated for categorical variables reflected association of the training course with change in management practices. Fisher's $\chi^{2}$ tests to compare pre- and post-training competencies addressed the small sample size. Statistical significance was set as $p<0.05$. Open-ended questions were transcribed and thematically analysed.

\section{Results \\ Quantitative results \\ Sample demographics}

A range of demographic/supervisory characteristics are reflected in Table 2. Of note, public-private participation was equal. Most participants were female $(80 \%)$ and nurses $(60 \%)$, half were in managerial positions for $<2$ years, and $70 \%$ reported no prior management training.

Reflecting on managerial roles (Table 3), the training was highly influential in areas of relevance to job roles (100\%), actions impacting on strategic achievements (80\%), and job augmentation (60\%).

\section{Competency self-assessment by CAHM graduates}

In pre- and post-training self-ratings of the 12 competencies (Fig. 1A and B), CAHM participants indicated considerable improvement in leadership and managerial skills after training. Areas of significant growth between pre-periods (T1) and post-periods (T2) were writing and evaluating strategic plans (T1-0\%; T2-90\%), assessing organisational design choices (T1 $-0 \% ; \mathrm{T} 2-90 \%)$, and obtaining funding for the organisation (T1 $-0 \%$; $\mathrm{T} 2-90 \%)$. Competencies, such as creating and implementing monitoring and evaluation plans, or creating budgets and performing budget variance analysis, were rated by participants as areas of significant growth. All competencies showed improvement after the course in self-rating (Fig. 1A and B). The smallest shift from pre- to post-training occurred in managing time effectively and leading individuals and teams.

\section{Stakeholder $360^{\circ}$ evaluations}

The $360^{\circ} \mathrm{E}$ by the supervisors, colleagues, and subordinates assessed 6 of 12 core competencies (Fig. 2). Agreement by two or more assessors on a particular skill is interpreted as competence in that skill; conversely, if only one assessor rates a participant as competent then the health manager is assumed to be incompetent in that skill. The $360^{\circ} \mathrm{E}$ affirmed that $80 \%$ of CAHM graduates were seen as competent to write and evaluate strategic plans; manage time effectively; lead individuals and teams; and develop and implement monitoring and evaluation plans after training. Additionally,

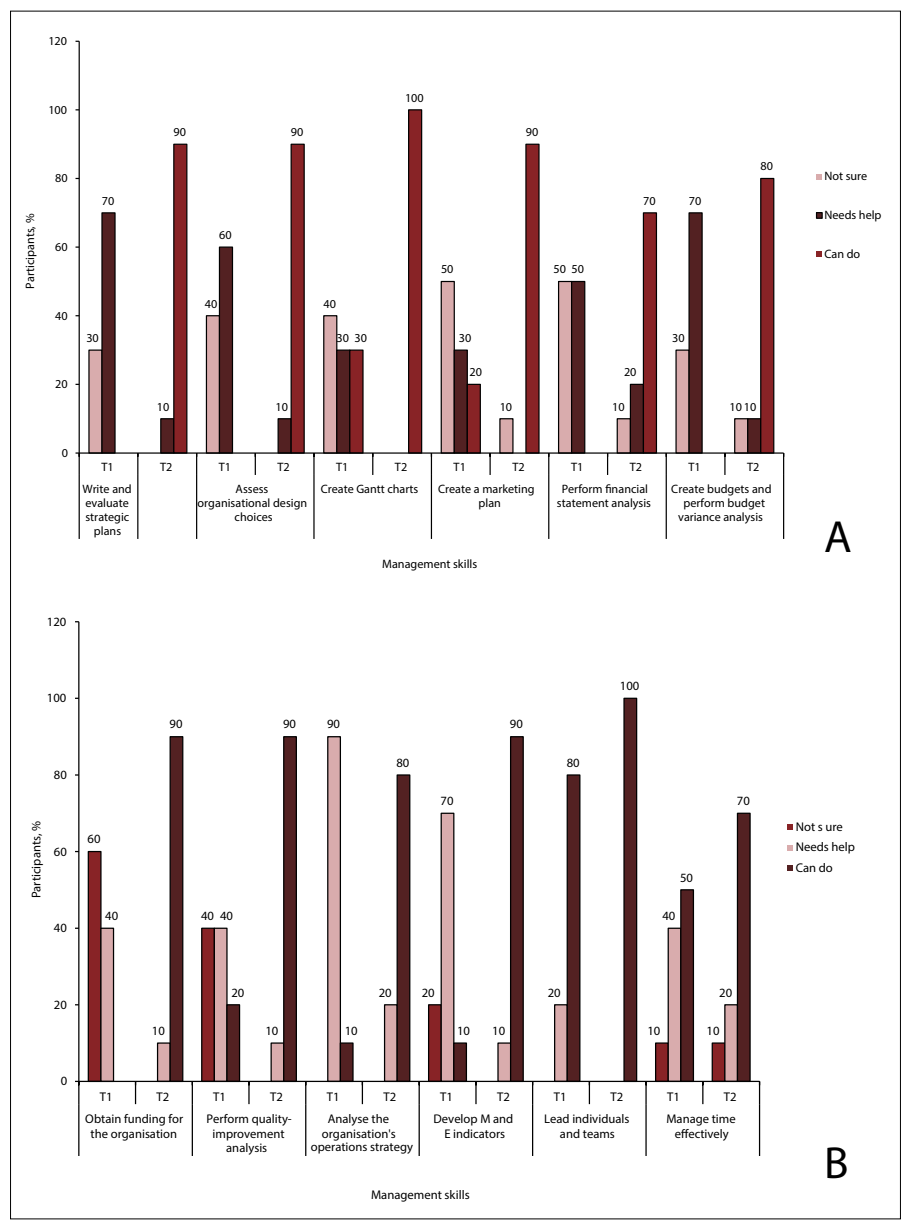

Fig. 1. (A and B) Self-rated competencies in select management and leadership skills before and after training. ( $T=$ time; $C A H M=$ Certificate in Advanced Health Management; $M=$ monitoring; $E=$ evaluation.$)$ 


\begin{tabular}{lll} 
Table 1. Domains for self-assessment & \\
\hline Domains & $\begin{array}{l}\text { Understanding } \\
\text { of a healthcare } \\
\text { environment }\end{array}$ & Managing yourself \\
\hline Leadership & $\begin{array}{l}\text { Strategic and } \\
\text { operational } \\
\text { management }\end{array}$ & Project management \\
Managing & $\begin{array}{l}\text { Resource mobilisation } \\
\text { and donor relations }\end{array}$ & $\begin{array}{l}\text { Financial } \\
\text { management } \\
\text { information }\end{array}$ \\
$\begin{array}{l}\text { Human resource } \\
\text { management }\end{array}$ & $\begin{array}{l}\text { Strategic marketing } \\
\text { and customer } \\
\text { relations }\end{array}$ & Action research \\
& &
\end{tabular}

Table 2. Demographic information for CAHM participants $(N=10)$

\begin{tabular}{|c|c|}
\hline Characteristic & $n(\%)$ \\
\hline \multicolumn{2}{|l|}{ Organisation type } \\
\hline Private & $5(50)$ \\
\hline Public & $5(50)$ \\
\hline \multicolumn{2}{|l|}{ Gender } \\
\hline Male & $2(20)$ \\
\hline Female & $8(80)$ \\
\hline \multicolumn{2}{|l|}{ Highest qualification } \\
\hline Diploma & $1(10)$ \\
\hline Bachelor's degree & $5(50)$ \\
\hline Master's degree & $4(40)$ \\
\hline \multicolumn{2}{|l|}{ Profession } \\
\hline Nursing & $6(60)$ \\
\hline Medicine & $4(40)$ \\
\hline \multicolumn{2}{|c|}{ Prior management training } \\
\hline Yes & $3(30)$ \\
\hline No & $7(70)$ \\
\hline \multicolumn{2}{|c|}{ Management role (years) } \\
\hline$<1$ & $1(10)$ \\
\hline $1-2$ & $4(40)$ \\
\hline$>2-5$ & $1(10)$ \\
\hline$>5$ & $4(40)$ \\
\hline \multicolumn{2}{|l|}{ Budget oversight (ZAR) } \\
\hline$>1000000$ & $5(50)$ \\
\hline $500000-1000000$ & $1(10)$ \\
\hline $100000-500000$ & $4(40)$ \\
\hline
\end{tabular}

$70 \%$ of respondents felt that the participants were competent in financial management. A negative difference occurred between the $360^{\circ} \mathrm{E}$ and selfrated levels of creating and implementing a marketing plan competency.

\section{Statistical significance}

It is possible that the small number of participants in the study affected the lack of statistical significance in comparing competencies at T1 and T2 (Table 4).

\begin{tabular}{ll} 
Table 3. Participants' perspectives on CAHM outcomes $(\mathbf{N}=\mathbf{1 0})$ \\
\hline Perspectives & $\boldsymbol{n}(\%)$ \\
\hline Recommend & $10(100)$ \\
$\quad$ Yes & $0(0)$ \\
No & \\
Relevance to work & $3(30)$ \\
$\quad$ Relevant & $7(70)$ \\
Very relevant & \\
Achievement of strategic targets & $8(80)$ \\
Yes & $2(20)$ \\
$\quad$ No & \\
Impact on current position & $1(10)$ \\
Better job offer/promotion & $1(10)$ \\
Promotion and increase in responsibilities & $4(40)$ \\
Increase in responsibilities & $4(40)$ \\
No change in job profile &
\end{tabular}

Table 4. Fisher's $\chi^{2}$ comparative test for management competencies (pre- and post-training)

\begin{tabular}{ll}
\hline Competency & $\boldsymbol{p}$-value \\
\hline Write and evaluate strategic plans & 1.00 \\
Assess organisational design choices & 0.40 \\
Create Gantt charts & 0.40 \\
Create a marketing plan & 1.00 \\
Perform financial statement analysis & 0.40 \\
Create budgets and perform budget variance analysis & 0.60 \\
Obtain funding for the organisation & 1.00 \\
Perform quality improvement analysis & 1.00 \\
Analyse organisation's operative strategy & 0.80 \\
Develop monitoring and evaluation indicators for projects & 1.00 \\
Lead teams and individuals & 0.40 \\
Manage your time effectively & 0.11
\end{tabular}

\section{Qualitative results}

Both CAHM participants and stakeholders provided feedback on their perceptions and experiences with the course. For the graduates, these comments aligned mainly with the impact on their work and use of action research as a tool. Stakeholder comments aligned with the impact of training on participants and potential recommendations of CAHM for future health managers.

\section{Impact on CAHM participants' work}

Reflection by CAHM participants on how the course affected their work was captured under three themes: successful programme implementation; job promotion; and work relationships. Five participants indicated that the skills learned through CAHM had practical implications for their ability to act and successfully implement a programme. The course enabled application of management skills in their work environments and projects such as skills-enabling proposal writing, improving approvals, and project implementation. One participant stated: 


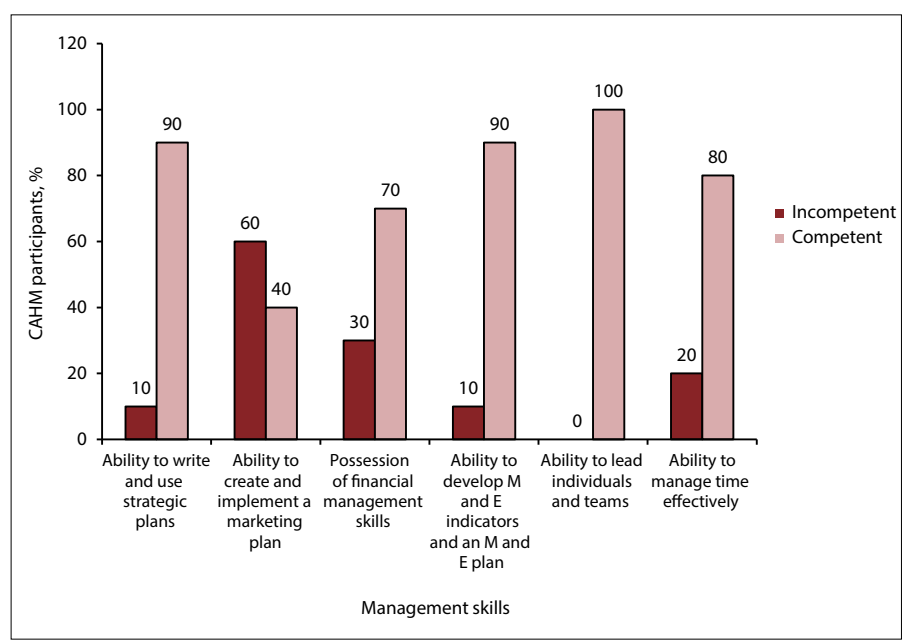

Fig. 2. Assessment $\left(360^{\circ}\right)$ on select competencies in leadership and management (post training). (CAHM = Certificate in Advanced Health Management; $M=$ monitoring; $E=$ evaluation.)

'I was able to submit my mentorship project to my organisation's top management in a more structured and comprehensive way and it was approved. The mentorship is actually happening .... '

Within the theme of job promotion, skills learned were very relevant and practical for health managers, making them more dynamic and effective change agents. Therefore, a competently skilled health manager is beneficial, as described by one graduate:

'I used the analytical methods of the CAHM to do strategic planning for the organisation and this resulted in a change for the organisation. And therefore I was given a new position.'

Four respondents' contributions informed the third theme, 'Better workplace relationships', highlighting participants' capacities to manage diverse people and situations. One participant observed:

'Dealing with and managing people is not an easy task ... I now possess people skills ....

Through CAHM, participants first understand themselves and how their presence has an impact, both negative and positive, on colleagues and subordinates, thereafter increasing awareness of relationships.

\section{Use of action research and problem-solving}

Action research is a practical tool that a manager can apply to identify and also solve a problem and prevent it from re-occurring. Not only does this approach improve the use and creation of evidence, but it also promotes dissemination of evidence within the workplace and beyond. Three themes were derived from the participant contributions related to the uptake and utilisation of action research: self-improvement; programme improvement; and work environment improvement.

Within the first theme (self-improvement), participants referred to the potential of using action research as part of one's career development, including dissemination of 'action research results to both national and international conferences'.

With regard to the second theme (programme improvement), participants indicated that this 'tool' was invaluable to their organisations' development. One participant stated:
'Through action research we have come up with better ways to control stock. A stock audit was performed at all sites and more than ZAR500 000 was saved through this exercise.'

As for the final theme (improving the workplace environment), action research can have an immediate effect and increase personnel involvement, as indicated in the following comment:

'Action research was used to improve the absenteeism rates in my workplace.'

\section{Impact of training on CAHM participants}

Through $360^{\circ} \mathrm{E}$, one recurring theme regarding the effect of the CAHM programme on participants was improved management and leadership skills'. The course increased participants' scope of management skills and extension of responsibilities, catalysing their visibility as leaders in their organisations and healthcare networks. Supervisors indicated that these individuals were now able to influence programmes within and beyond their own workplace by 'effectively leading a team of peer educators ... [and] successfully networking with partners'. Colleagues indicated that CAHM graduates have garnered increased respect owing to improved quality of work (e.g. being very professional and very thorough) and increased levels of confidence in their work. This was evidenced as follows:

'The CAHM sharpened and enhanced the participant's managerial skills in general ... added more substance to the content of his knowledge on the principles of leadership and management.'

Subordinates indicated that CAHM graduates improved the work environment, impacting on the quality and levels of team participation. Subordinates also found evidence of application of technical skills after the CAHM course in areas such as development of practical organisational strategic plans. A respondent described this as follows:

'The strategic plan she has developed and uses was much needed by the company and the community. She has involved the entire team in the project and everyone is given a chance to contribute their thoughts.'

\section{Assessors' perspectives on recommending CAHM}

In stakeholder recommendations on CAHM for future candidates, two key themes emerged: positive impact due to training; and need for training in management. Supervisors and colleagues recommended CAHM, as it contributed to significant growth in skills and capacities of the graduates. One of the supervisors stated:

'The impact and change the course has brought to those exposed to it is of great value.'

Regarding the second theme (need for training for managers), both colleagues and subordinates commented on the positive impact of the training on the wider workforce. According to one respondent:

'The CAHM unfolds your potential. All managers need it.'

\section{Discussion}

The key result from participants' self-rated competencies and the $360^{\circ} \mathrm{E}$ is that participation in CAHM led to improvement in graduates' leadership and managerial skills. Self-rated competencies indicate that, after training, $\geq 70 \%$ of participants were competent in each of the 12 management skills. Similarly, the $360^{\circ} \mathrm{E}$ confirmed competency in five of the six explored management skills, with an evaluated competency level of $\geq 70 \%$. 
Self-rated competency on finances was low, possibly attributed to gender differences in self-ratings. Female self-rated competencies were lower than those of males in several areas. Furthermore, organisations do not focus sufficiently on health managers having skills to manage business complexities of client care, such as budget management. ${ }^{[9]}$

The $360^{\circ} \mathrm{E}$ compared perceptions of stakeholders to provide the assessed individual with a clearer picture of strengths and weaknesses, and to clarify expectations. It increases reliability of individual self-ratings. The $360^{\circ} \mathrm{E}$ monitors progress, with identification of training priorities and coaching interventions. ${ }^{[13]}$ In this assessment, participants scored poorly in the creation of a marketing plan and its implementation.

\section{Study limitations}

In terms of study limitations, 44 individuals participated in the CAHM; however, only 17 were health professionals and met our inclusion/exclusion criteria. The small number of participants had an impact on statistical significance and limited generalisability of results. Furthermore, this study involved primary collection of data through self-administered questionnaires; therefore, the data were subject to recall information bias.

\section{Conclusion and recommendations}

Graduates and key stakeholders perceived training in an advanced management course, such as CAHM, as beneficial to health professionals in Gauteng. Our data indicate improvement in areas of leadership, financial management, monitoring and evaluation, strategic planning, and time management. Competency to develop a marketing plan was positively self-rated by health managers, but was not viewed as a realised competency by the $360^{\circ} \mathrm{E}$. All trained health managers indicated that the course was relevant or very relevant to their work and highly recommended it for other health managers. This was mirrored by stakeholder comments, which also recognised the positive impact of the CAHM on health managers and recommended it to other managers in the health sector.

Further research is needed with a larger sample to address statistical significance and generalisability. This study only considered six of 12 management skills in the $360^{\circ} \mathrm{E}$ and should be expanded to all 12 in a future study iteration. The $360^{\circ}$ assessment tool was considered a strength in this study; hence, future use and implications of this approach should be further explored. Finally, the potential to compare impacts and implications with management/leadership across sectors is possible given the mix of participants in the CAHM programme.

Acknowledgements. We thank the following contributors to the study: Profs S Manda, A McIntyre, T Mampe and B English. We also thank the Foundation for Professional Development (FPD) for their permission to conduct the study at their institution.

Author contributions. JM: involved in all aspects of this project from inception through publication; FS, DC, VP: supervised tool development and the research process; and PP: involved in the analysis and dissemination phase. All authors contributed to the final publication and editing.

Funding. None.

Conflicts of interest. The researcher (JM) was employed by the FPD at the time of the study. The FDP supports this journal.

1. Strack van Schijndel RJ, Burchardi H. Bench-to-bedside review: Leadership and conflict management in the intensive care unit. Crit Care 2007;11(6):234. https://doi.org/10.1186/cc6108

2. Green TP. Management skills of intensivists influence outcomes in pediatric intensive care units. Pediatr Crit Care Med 2007;8(6):587. https://doi.org/10.1097/01.PCC.0000288707.41243.F1

3. Harrison T, Gray AJ. Leadership, complexity and the mental health professional. A report on some approaches to leadership training. J Ment Health 2003;12(2):153-159. https://doi.org/10.1080/0963823031000103461

4. Ersson A, Chew M. Evidence-based approach to intensive care unit management: Need for improvement. Crit Car 2008;12(1):404. https://doi.org/10.1186/cc6763

5. Nielsen K, Yarker J, Brenner SO, Randall R, Borg V. The importance of transformational leadership style for the well-being of employees working with older people. J Adv Nurs 2008;63(5):465-475. https://doi.org/10.1111 .1365-2648.2008.04701.x

6. McLarty J, McCartney D. The nurse manager: The neglected middle. Healthcare Finan Manage 2009;63(8):74-78 7. Reed S. Ward management: Education for senior staff nurses. Paediatr Nurs 2008;20(3):27-31. https://doi.org/10.7748/ paed2008.04.20.3.27.c6518

8. Dwyer AJ. Medical managers in contemporary healthcare organisations: A consideration of the literature. Aust Health Rev 2010;34(4):514-522. https://doi.org/10.1071/AH09736

9. Dierckx de Casterle B, Willemse A, Verschueren M, Milisen K. Impact of clinical leadership development on the

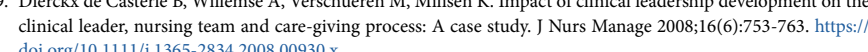

10. Pillay R. Managerial competencies of hospital managers in South Africa: A survey of managers in the public and private sectors. Hum Res Health 2008;6(4). https://doi.org/10.1186/1478-4491-6-4

1. National Department of Health. Strategic Plan 2010/11 - 2012/13. Pretoria: NDoH, 2014.

12. Foundation for Professional Development. Certificate in Advanced Health Management. Study guide. Pretori FPD, 2009.

13. Kim PS. Utilising 360-degree feedback in the public sector: A case study of the Korean central government. Asian J Pol Sci 2001;9(2):95-105. https://doi.org/10.1080/02185370108434193

Accepted 11 July 2016. 